Portland State University

PDXScholar

$12-21-2021$

\title{
An Instructional Guide to Environmental Campaigns for K-12 Schools
}

Erin McCarty

Portland State University

Follow this and additional works at: https://pdxscholar.library.pdx.edu/honorstheses

Part of the Educational Assessment, Evaluation, and Research Commons, Educational Methods Commons, and the Environmental Education Commons Let us know how access to this document benefits you.

\section{Recommended Citation}

McCarty, Erin, "An Instructional Guide to Environmental Campaigns for K-12 Schools" (2021). University Honors Theses. Paper 1157.

https://doi.org/10.15760/honors.1192

This Thesis is brought to you for free and open access. It has been accepted for inclusion in University Honors Theses by an authorized administrator of PDXScholar. Please contact us if we can make this document more accessible: pdxscholar@pdx.edu. 
An Instructional Guide To Environmental Campaigns For K-12 Schools

by

Erin McCarty

An undergraduate honors thesis submitted in partial fulfilment of the requirements for the degree

of

Bachelor of Science

in

University Honors

and

Communication

Thesis Advisor

Dr. Brianne Suldovsky

Portland State University

2021 


\begin{abstract}
Evidence suggests environmental education can correlate with both short-term and long-term behavioral changes, but existing research on the effectiveness of popular environmental education tactics show mixed results. Qualitative research was used in this study to assess student engagement and behavior change from the perspective of environmental educators within the context of environmental campaigns. Ideally, students exposed to environmental education campaigns become more informed on environmental issues and adjust their behavior to align with the campaign's objectives. However, only a portion of environmental campaigns have the intended effects. Based on a preliminary literature review, the level of student involvement in the learning and teaching process was the anticipated defining catalyst on post-campaign behavioral engagement. Exploratory interviews with environmental educators presented three key factors in changing a child's attitude and behavior toward the environment: involvement, connection to the local community or ecology, and student enjoyment.
\end{abstract}

\title{
Key Terms and Variables
}

Environmental education (campaign): lessons designed to increase student's understanding of the natural world while promoting environmentally-conscious behavior

Pro-environmental behavioral change: when the student continues to incorporate campaign information into their lives two or more months after the end of the campaign

- Utilizing campaign information without being asked to do so

- Behavior reflects some or all campaign objectives

K-12 students: children enrolled in a school system between the ages of 5 and 18 years of age; kindergarten through twelfth grade 


\section{Introduction}

Earth's climate is changing faster than ever before, and the causes are widely attributed to human activity (NASA, 2021). Drastic behavioral changes are needed to mitigate the impact of climate change. The immense magnitude of the issue has spurred global interest in environmental education, particularly for children (Monroe, et al., 2017). Global interest led to the 2015 United States amendment to the Secondary Education Act titled No Child Left Inside. This amendment allocated federal funding for environmental educator training and the development of a more robust and inclusive environmental cericula (114th Congress, 2015). The intent of environmental education is, at least in part, to increase a child's environmental awareness and develop their connection to nature which should in turn, influence pro-environmental behaviors in their daily life (Otto \& Pensini, 2017). This educational pursuit has taken many forms in the last thirty years, but does teaching children about the environment actually increase their awareness and pro-environmental behavior? A preliminary assessment of environmental education studies has shown mixed results in regards to their measurable impact (Saylan \& Blumstein, 2011).

Environmental researchers and educators who studied environmental education have identified two factors that are believed to influence a child's environmental behavior. Although they have been observed and measured in many different ways, the two key factors are generally described as environmental knowledge and personal connection to a location or group (Chawla \& Flanders Cushing, 2007; Otto \& Pensini, 2017; Beane, et al., 1981). Popular teaching tactics for increasing knowledge and local connections often include outdoor learning and community-based projects (Otto \& Pensini, 2017). Disagreement within the discourse 
community, however, revolves around the effectiveness of these tactics. For example: an investigative study conducted in Australia found outdoor learning significantly increased the student's environmental behavior (Ballantyne \& Packer, 2002). Alternatively, a meta-analysis of environmental education, both within the classroom and outdoors, found traditional classroom-based learning lead to significantly greater increases in environmental behavior (Zelezny, 1999). Differing results of this nature are present throughout the discourse community. An investigative survey by Volk, Hungerford, and Tomera found "a consensus among the professional participants that the [environmental education] goals are important ones, [but] they are not being met to a large extent in existing curricula" (Volk, Hungerford, \& Tomera, 1984, p. 10). Additionally, a similar study by Monroe et al. found environmental education campaigns lacked an interdisciplinary approach needed to create profound practical changes (Monroe et al., 2017). And yet numerous studies have found substantial behavioral benefits as the result of environmental campaigns (Chawala \& Flanders Cushing, 2007; Paterson \& Elliott, 2006; Otto \& Pensini, 2017).

Part of the reason for the conflicting results of prior studies may be due to the challenging nature of this type of research. For example, behavioral changes are difficult to measure with traditional survey methods due to the highly nuanced nature of human behavior and the time needed to assess short-term vs. long-term change (Ballantyne \& Packer, 2002). Educators are uniquely qualified to observe behavioral changes in their students without priming them with survey questions. Through a series of exploratory interviews with environmental educators, recurring themes were identified in relation to effective environmental education. The most effective environmental education campaigns discussed in the interviews involved some amount of 
in-class academic involvement (reading, discussion, leading other students, etc.), a hands-on component, an element of fun, and most prominently they were all heavily related to the local community.

\section{Methods}

Preliminary research into environmental education identified several noteworthy campaigns from around the world which served as the basis for participant recruitment and built the foundation of knowledge for this study. Snowball sampling was used to increase the initial participant sample size. Interview protocol was designed to compare multiple aspects of environmental campaigns and identify which tactics worked and which did not. Campaign aspects that were of particular interest were: campaign objectives, methods of implementation, and results. The interviews were transcribed, coded for recurring themes, and analyzed to identify relationships between environmental education perspectives.

\subsection{Population}

The population chosen for this study were grade school teachers and community educators who have experience with environmental education campaigns designed for children ages 5-18 years old. This population was selected for their invaluable perspective and insight on environmental education. A focus was placed on educators from non-western countries in order to include perspectives that have historically been overlooked by western academia (McGregor, 2009). Participants were selected from the campaigns studied during preliminary research. Such research included a 2020 webinar on childhood environmental education gathered educators from around the world to speak on their experience with environmental campaigns. This webinar curated international perspectives and provided the contacts for potential participants. 
IRB-approved recruitment emails were sent to over thirty institutions and individual educators. Participant recruitment emails included an informed consent agreement that clearly stated the terms and conditions of the study. No incentive was offered to participants and there were no consequences for declining to participate or withdrawing from the study. Three initial participants were confirmed from preliminary research. From these initial participants, two additional participants were confirmed on request via snowball sampling.

\subsection{Interviews}

All interview questions were open ended and structured to mimic casual conversation. The objective was to uncover the details behind environmental education that could bring some clarity to the incongruity within the discourse community. It was critical to make each participant feel comfortable enough to share their honest opinions. Interviews were conducted over Zoom. The call would begin with a casual greeting and gratitude for their willingness to participate. Then the call was recorded and the scripted introduction of the interview was recited to remind the participant of their right to withdraw from the study without consequence and their right to participant anonymity.

\subsubsection{Interview Protocol}

1. Can you tell me about your job and the kids you work with?

2. Tell me about your most recent environmental campaign?
a. Why was this campaign implemented?
b. What was your role?

3. What were the campaign goals and objectives?

4. What parts of the campaign did students participate in?

5. How did students react to the campaign? 
a. What aspects of the campaign did students like the most?

b. What parts of the campaign did students dislike, or express apathy towards?

6. What aspects of the campaign were particularly effective, if any?

7. Which aspects of the campaign were ineffective, if any?

8. How would you measure success in the context of this campaign?

9. If you were to give advice to other educators looking to participate in an environmental campaign, what would you say?

The first question (Can you tell me about your job and the kids you work with?) was intended to break the ice and start the conversation. This was how the interviews started, but after this point the protocol order was unique to each participant. Adjustments to the protocol were made to foster the natural flow of conversation. Participants would often answer questions before they had been asked simply because that was how the conversation unfolded. Notes were made throughout the interviews whenever a participant expressed heightened emotions, such as excitement, passion, frustration, or remorse. Additional notation was added when participants repeated a topic or theme. These handwritten notes captured initial impressions and a preliminary analysis of the participant's perspective. Interview length ranged from twenty-two minutes to fifty-six minutes, lasting an average of forty-one minutes.

\subsection{Transcription}

Each interview was a one-on-one conversation conducted through the video call platform, Zoom. Audio files from the interviews were captured on three devices to ensure data security. Zoom's internal audio recording, Google Recorder, and a third party Voice Recorder application were used during each interview. Google Recorder automatically transcribed the audio from each interview, but the transcription software was not equipped for the multiple dialectical differences 
represented by the participants. All automated transcriptions were cross referenced with the audio files and corrected. This process of reviewing all the recorded data (both audio and written transcripts) revealed certain repeating themes that pertained to the research question. These themes were then defined and converted into the codebook below.

\subsubsection{Codebook}

Academic Involvement: students have an active role in the learning or teaching process; this typically takes place within the classroom; examples are reading, discussion, debate, or teaching other students

Hands-On Involvement: students physically engage with the lesson material; this can happen in or outside of the classroom; examples are gardening, caring for an animal, or crafting

Local Connection: how the lesson relates to the surrounding area or community; the locality can be as small as a classroom, but typically ranges in size from a single school to a county

Campaign Highlights/Children's Favorite Part: aspects of the campaign or lesson that the children enjoyed the most

Advice: helpful tips and teaching tactics for other environmental educators

What To Avoid: teaching tactics that did not work or lead to adverse effects

\subsection{Thematic Analysis}

Corrected transcripts and the codebook were input into the data analysis program, Dedoose. Thematic analysis began with a round of open coding in which each transcript was reviewed and color-coded. Excerpts that reference themes in the codebook were color-coded to reflect the specific theme. Some excerpts were coded with multiple themes. After open coding was completed, the codebook was revised to reflect relations between the themes. This process is 
referred to as axial coding. The first three themes were weighted with a 1-2 scale to more accurately depict the applied code's intensity. Excerpts from the transcripts that directly referenced a specific theme were coded with a 2, while excerpts that loosely related to that theme were coded with a 1. The Campaign Highlights/Children's Favorite Part, Advise, and What To Avoid themes were not weighted because all excerpts coded as such were in equally certain terms with no differences in intensity. Additionally, the What To Avoid theme was embedded as a child code under Advice. This was because all excerpts coded as What To Avoid also fit within the Advice theme. The two themes were not fully combined because a portion of the Advice excerpts were positive suggestions. The transcripts were then reevaluated with the adjusted codes. Upon further analysis, the themes were collapsed into three intersectional macro themes: involvement, connection, and enjoyment.

\section{Results}

This section presents the results of the qualitative interviews. Overall, results indicate that active involvement, connection to place, and enjoyment were all perceived by environmental educators to be vital components of a successful educational program.

\subsection{Involvement}

According to the participants, environmental education campaigns are most effective when the lesson plan requires students to participate. Having students read a storybook or novel that relates to the environmental issue at hand is an easy way to introduce them to emotionally weighty topics such as climate change. The familiar medium of a fictional story can help students conceptualize complex environmental problems through the lens of a relatable 
protagonist. Some participants wrote their own storybooks to illustrate the issues impacting the student's local ecosystem. Their environmental storybooks were coveted by the young students in their campaign. Other participants sourced fiction novels for older students that described the rise of industrialization in order to analyse a root cause of an environmental issue. Regardless of the student's age, they should all be encouraged to discuss what they learned and how they perceived the message.

\subsubsection{Discussion and Debate}

Encouraging students to discuss the environmental message within a book has a variety of benefits. Through peer-to-peer discussion, students can explore their own perception of the issue and potentially identify their personal perspective. This is a critical step towards relating environmental issues to the child's lived experience. It is an educational component that intersects with the Connection macro theme. Discussion can also lead students to uncover their feelings associated with the environmental topic. One participant stated, "[It] is more a learner trying to bring out what they are interested in when they read a storybook." In a safe social space that fosters emotional tolerance, discussing feelings about environmental topics can increase comradery between peers. Finally, discussion is an effective method of measuring the students' understanding of the topic. It is an opportunity for students to ask questions and for educators to correct misconceptions.

Environmental debates can be beneficial in ways similar to discussion, but debates incorporate two additional components. The first component is that debates challenge students to consider perspectives they are unfamiliar with or outright disagree with. Very few environmental issues have simple solutions, so students that are given the freedom to develop their own interpretation 
often bring a wide variety of ideas to the debate table. In order to effectively argue one's point, the student must consider their opponent's ideas and perspective. This level of critical thinking can greatly increase the student's understanding of the topic and their willingness to discuss complex environmental issues. It also has the potential to increase the student's empathy toward alternate environmental views.

The second and most obvious component of debate is competition. While the process is more suited to groups of students who are already accustomed to competition, a friendly debate can encourage students to think more critically about the topic in order to win the debate. Multiple participants stated the positive impacts of friendly debates. One participant even orchestrated a mock-United Nations climate debate in which students from multiple schools spent weeks debating a variety of environmental topics before the top debaters were brought together to debate climate action strategies. This education tactic is intersectional among all three macro themes.

\subsubsection{Songs and Student Interests}

Singing songs is another method of bringing students into the environmental education process. Multiple participants noted that songs and rhythmic rhymes were extremely effective tools to increase the student's comprehension. One participant described the impact of environmental songs; "we can go into a classroom and teach a whole lesson and then a month after, go back and ask them like what they remember about a particular lesson and it'll always be a song because the song relates to the lessons, you know?" According to the data, singing and reciting rhymes lies firmly between Involvement and Enjoyment. Although this teaching tactic is commonly used with younger students, some participants claimed similar improvements to lesson comprehension 
in older students through the use of songs and rhymes. One participant actively encouraged older students to write original songs that reflected the environmental message. Their songs were performed in the talent showcase portion of an environmentally focused festival.

The same talent showcase reflected a variety of student interests, all presented through an environmental lens. Some students designed their own fashion pieces made from recycled materials and natural fibers. Others showcased their visual art skills with painting of environmental systems. Each student was encouraged to take what they were already interested in and make it environmentally conscious. This teaching tactic gives the individual student total creative control to express their relation to environmentalism. It can be highly motivating to some students and heavily intersects with the Enjoyment theme.

\subsubsection{Responsibility}

Another intersectional tactic is to give the students responsibility. One participant shared an example of this in the form of a worm farm. Each classroom was given a worm farm to care for and learn from. At first, the young students were all too squeamish, but by the end of the program every student was fully invested in the health of the worm farm. Every week, students learned different aspects of the compost process. First they learned about the worms and their important role in decomposition. When they learned what the worms like to eat, they were asked to bring scraps from home to feed the farm. The participant noted how some parents had asked their children to explain why they needed food scraps for school. They also described how enthusiastic the students were while they taught their parents about worms and the importance of composting. Through the campaign, students also gained knowledge on how to identify signs of poor worm farm health and how to troubleshoot. This hands-on involvement in the lesson 
provided the students with ways to use their knowledge and relate the environmental lesson to real objects they cared about (the worms).

Caring for plants can also serve as a source of responsibility for students. Tree planting was the most frequently mentioned form of hands-on involvement by the participants. In some cases, a tree was planted in a central location at the school, and was available for all of the students to tend to. Other cases had one tree for every grade level or every classroom, and one case involved giving a tree seed to every student for them to plant at home. Each case involved an educational component about deforestation, air pollution, the life cycle of a tree, and other relatable topics. The most important factor when using the tree planting tactic is to place the burden of care on the students. This includes giving the tree a name. If possible, let the students decide what tree they want. One participant claimed that the more control students have in the decision process, the more likely they are to care for the tree. Another participant mentioned visiting a school months after each grade had planted their trees, only to find the students had turned the whole campaign into a competition. They were comparing the growth of each tree and trying everything they could to make theirs grow bigger and faster. Fruit trees are especially well-suited for this tactic because the students are incentivised by the reward of a tasty fruit.

Similarly, tending a garden is another great hands-on method of environmental education. Three participants described the multitude of benefits that come from community gardens. In most cases the garden was located on school grounds and was tended to by many different classes. The students chose seeds from a list of plants suited to their climate and were responsible for garden maintenance. Much like the tree planting cases, each class that tended the garden learned 
the environmental processes they were facilitating. Younger students focused on the water cycle and life cycle of a plant, while older students learned about carbon sequestration. Some teachers would read to their students in the garden or take them there for snacks. Every participant stressed the importance of letting the students explore their connection to the soil and plants in order for them to form the mental connection between themself and the environment. This tactic is ubiquitous in all macro themes.

\subsubsection{Cross-age Teaching}

The age divide between students in the garden prompted the faculty to implement a student mentorship program in which older students would teach younger students environmental topics. This tactic is widely used to assist students with developing reading skills. Older students with reading struggles are paired with young students who have also displayed similar struggles with reading. The younger student not only benefits from the additional practice, but they are often more receptive to the teaching tactics of an older peer who has experienced similar struggles. A qualitative study on cross-age tutoring by Patterson and Elliot found the older student often "shifted their perspective to see themselves as increasingly competent role models, and applied their developing reading abilities as they selected and modified strategies based on the needs of their younger students," (Patterson \& Elliot, 2006). Cross-age tutoring has proven to be incredibly effective at increasing both the tutor and the student's understanding as well as their willingness to engage with the lesson. The same effect was observed by the participant who brought cross-age tutoring to their environmental education program.

\subsection{Connection}

Connecting the environmental education campaign to the local environment was the most frequent theme and its importance was heavily stressed by all participants. One participant 
stated, "Start with something very familiar. Start with an issue that's existing within that community instead of bringing foreign concepts." At the youngest level (Kindergarten), students must first grasp a basic knowledge of environmental elements (i.e. soil, water, plants, animals, sunlight, etc.). This level of environmental education is relatively easy to connect to the students' locality. Most of these can be observed simply by bringing the students outside. According to the participants, some environmental educators lose this connection as grade levels rise. One participant recounted an environmental education evaluation they conducted in a neighboring country. The school was located in a landlocked country, the students were five and six years old, and the lesson was basic ocean ecology. The teacher described the ocean, the beach, the waves, and other generic details to the young students. The teacher then pointed to the ocean on a map and asked a student what it was; the student confidently replied, "a map." In order to effectively teach young students, educators must start with what the students already know. Presenting students with the least amount of foreign concepts at any one time reduces additional challenges to the learning process. While understanding different biomes is certainly important, each participant agreed it is best to build off the knowledge and experiences that students bring to class.

\subsubsection{Local Reminders}

Relating environmental lessons to the student's locality can also serve as a repetition-style study tactic. When an environmental educator explains the water cycle within the context of water level changes in a local pond, their students will hold that connection in their mind. When their students walk past the pond and see water lines above the water surface, they will likely remember the water cycle lesson. This tactic was used by each participant that facilitated a tree planting. The trees the children planted on their campus served as a reminder of the lessons they 
learned. One participant facilitated a student-led tree planting at a local church (attended by many of the students), and every time they went to church with their families the students would check on the tree. Another participant incorporated competition into this tactic.. "So one [tree] for every class and we would create a friendly, healthy competition... So by the end of the day, the objective was (apart from the consciousness you're putting in their minds) you give them ownership and you also create fun while doing it, which is what children want." Local connections are not always ecologically focused. Some participants stressed the importance of community connections as well.

\subsubsection{Social Impact}

Environmental issues affect each community in unique ways and require proportionately unique responses. When designing an environmental campaign, it is imperative to tailor the messages and the lessons to the issues that affect the student's community. One participant described rises in temperature and how the students had no shade cover or greenspaces on their campus; they in turn, integrated tree planting and gardening into their pre-existing environmental education program. Another participant described the lack of fresh food available to the underserved parts of their school district, so they began teaching students how to harvest and grow fruit from seeds. By educating students on seed germination and plant life cycles, the students were able to bring fresh fruits and vegetables to their families. Children respond to knowledge that affects them and their community. Young students can spark change when given the knowledge and efficacy to improve their environment.

While tree planting and gardening are excellent environmental education tactics for all ages, learning to assess and address a holistic view of the local ecology is much more effective and 
engaging with older students. Multiple participants claimed that the communities they work with have ignored the critical role that elders play in environmental education. The impact of generational wisdom on human evolution cannot be overstated. For centuries, elders have passed a wealth of knowledge to the youths so they may learn to cultivate the land and live in a manner that can sustain their shared community. The absence of this generational wisdom, as observed by participants, is an international phenomena that has garnered academic inquiry. A recent study into the loss of traditional ecological knowledge in Japan found that younger generations are in fact less knowledgeable than previous generations were. The researchers attributed the loss of knowledge to changes in communication channels and a lack of experience (Okui, Sawada, \& Yoshida, 2021). Community elders as a group often possess environmental knowledge that is highly specific to the local area. With the right communication, they may impart their wisdom unto interested students.

\subsubsection{Case Study for Older Students}

One participant specialized in designing community-based environmental education programs, and their advice for any educator looking to do the same is to start with the elders. Ideally, community elders would gather with the older students and discuss what the local ecology looked like over fifty years ago. As the elders take turns describing the environment of their childhood, students take notes. The elders and the students then discuss the differences between then and now and possible causes. This process typically works best with a moderator to ensure everyone is heard and all questions are answered. When the students inquired about the lack of rain, the participant told them "Go back, 50 years, 100 years. Ask your elders, Where were the falls? Where were the river beds? How did it dry? What has happened to the terrain?" With the information from their community elders, the older students work with the environmental 
educator to identify the problems and where to focus their attention. The beginning stages of this process require close collaboration with the environmental educator, but the students must retain a degree of creative control and decision making power.

This first analysis stage is an excellent opportunity for students to connect the elders' knowledge to the land by visiting the locations they have chosen to focus on. The participant who described this process recounted a case where some of the elders offered to visit the site with the students. They were able to point out the sparse remains of native plants along a dry creek bed that were directly responsible for preserving healthy streams and waterways. Although bringing elders on field trips is not always possible, it is preferable as it increases the connection between both the students and the community to the project.

Once a problem and corresponding cause has been identified, the environmental educator should encourage the students to work together to find a solution. In the previously mentioned case, the solution was to plant the native plants near the base of the creek so they could catch the coming rain. Ecological problems typically have multiple causes that impact each other, so the environmental educator must make sure to inform the students of the potential impacts of their actions while encouraging them to strive for ecological restoration. The participant summarized the process as "discussions, stories, and then hands-on identification, and then solutions together." While brainstorming solutions, students must ensure their plan is falsifiable. Results that cannot be measured or observed provide little educational value. Another bit of advice from the participant who described this process is to be wary of using machinery to engineer or alter the original landscape (the phrase "original landscape" is in reference to the landscape described 
by the community elders). Cultivating the land should be done incrementally to mitigate the possible fallout of a misconception or misjudgment in the planning.

\subsection{Enjoyment}

The final macro theme has been present to some degree in every environmental education tactic mentioned thus far. One way to foster interest in environmental education is to make it fun and engaging. "They love excitement, fun, playing. So you show them that conservation can be fun, but we have to take care where we want to have the fun." This may seem obvious, but the element of fun is often a missing component of environmental education campaigns. Lesson plans are designed by adults for children, so it is crucial to know what children are interested in and what they enjoy. What is fun or entertaining to a teacher is not always fun or entertaining to the student. Educators may think their students would enjoy a trip to a local park, and the educator may be right, but if the educational content is not interesting to the student - the message will likely leave their brain shortly after they leave the park. Every participant shared this perspective. Educators must know their audience well, especially when implementing an environmental campaign.

Enjoyment was qualified as a macro theme not only due to its prevalence within the data, but also because of the amount and intensity of participants advising against its inverse. Every participant made multiple mentions of ineffective teaching tactics. During the thematic axial analysis of the transcripts, it became clear that all ineffective teaching tactics were notably unenjoyable for students. Multiple participants shared their experience of working within an environmental education campaign that did not foster an enjoyable learning environment. These participants were compelled to leave their position when it became clear the unappealing nature 
of the campaign would continue. The most frequent and severe warnings about ineffective, poorly implemented campaigns involved teaching tactics that the students found boring, tactics that instilled fear, and messaging that placed blame or shame on the students or their community.

Examples of "boring" campaigns described by participants incorporated little, if any, student involvement and were short-lived. Environmental education campaigns with little to no involvement often rely on lectures and are structured with a teaching style that is synonymous with core curriculum. Educators who are truly invested in the effectiveness of their campaign and their students' attitude towards the environment must shoulder both the standard responsibilities of a teacher as well as the added burden of presenting the information in a way that their students enjoy. One way for educators to lighten the aforementioned burden is to build up their own passion for environmentalism. This perspective was shared unanimously among participants. Two participants claimed students often reflect the enthusiasm of the educator, and they strongly advised any environmental educator to take stock of their own feelings about the topic and its implication before presenting to the children.

A boring lesson is unlikely to inspire a positive attitude change, but environmental lessons that instill fear or shame can produce far worse results. It is all too easy to slip into a negative perspective when discussing topics like the climate crisis. Those who understand the stakes often carry the weight of stress, anxiety, and/or depression associated with the threat of climate collapse. One participant stated the importance and the reality of these feelings. Another participant regularly encourages their fellow educators to sit with these feelings and understand how they affect their perspective on environmental issues. Some people do not even realize 
when they put their negative perspective on others. A subtle, yet common example of this occurs when people claim to not recycle because it does not make a difference. Even if their own trash is a negligible drop in the bucket, the underlying message is that the individual cannot change the course of events. Messages such as these are in complete opposition with the goal of empowering children with the knowledge and skills to improve their environment.

One participant claimed that no matter what, students will eventually be exposed to the dire stakes of climate change, and so it is the duty of the educator to cultivate a resilient environmental attitude within each student to prepare them. Lessons about environmental problems that focus on the cause instead of solutions can lead children to make detrimental connections in their mind. An example provided by a participant was if a child were to make the connection between the car that gets them to school and air pollution, they might be forced to reconcile the cognitive dissonance that either their family is to blame for air pollution or their teacher is not telling the truth. Even within a positive campaign, some students will likely discover this mental struggle. It is imperative that environmental educators have a comprehensive understanding of their own feelings so that they can help students cope with the same fears.

\section{Discussion}

First-hand experiences are not generalizable, but they expose struggles and triumphs faced by the participants. The major findings of this study have been summarized into a brief list of guidelines for environmental educators. 
Before teaching environmental education, asses your own feelings about the environment

Incorporate generational wisdom in lessons and projects

Connect lessons to the local ecosystem or community

Bring students into their local ecosystem

Give students an experiential activity to do during lessons and projects

Implement projects that will affect the students or their community

Encourage students to explore their understanding and perspective of the lessons

Give students responsibility within the lessons and projects

Make lessons and projects enjoyable for the students

\section{Limitations and Future Research}

This study was impacted by the covid-19 pandemic, technological limitations, academic limitations, and my personal biases. Social distancing caused most environmental education campaigns to pause, so participants discussed information from previous years. Some potential participants had been laid off during the pandemic and were no longer reachable. Many educators were teaching remotely and were unwilling or unable to participate. Those who did participate were interviewed through Zoom and some of their information was inaudible due to internet connections failures. These instances are marked as [inaudible] in the transcripts.

The process of transcribing audio data has a higher chance of accuracy when multiple researchers work together. An Honors Thesis, however, must be done alone. This also impacted 
the interpretation of the transcripts. Qualitative research requires interpretation to draw meaning from data. A collaborative process called investigator triangulation is often implemented to bring multiple interpretations together in order to draw meaning that more closely aligns with the speaker's intent. As the sole researcher, my perspective was the only lens through which data was analysed. Additionally, participants were selected from a variety of countries in order to include perspectives that are often overlooked by Western academia. While this remained my intention throughout the study, I am deeply entrenched in Western academia and must address the inherent biases I brought to the study as a white college student in Portland, Oregon.

This study was also limited by the nature of qualitative research. These findings cannot measure efficacy or change. They can only provide a deep look into the personal experiences of environmental educators. Further research is needed to compare the effectiveness of environmental teaching tactics. In order to derive generalizable data, additional research should include substantially more participants, a team of researchers, and a quantitative investigation. 


\section{References}

114th Congress. (2015, April 29). H.R.882 - 114th Congress (2015-2016): No Child Left inside Act of 2015. Congress.gov | Library of Congress. https://www.congress.gov/bill/114th-congress/house-bill/882

Beane, J., Turner, J., Jones, D., \& Lipka, R. (1981). Long-term effects of community service programs. Curriculum Inquiry, 11(2), 143. https://doi.org/10.2307/1179705

Ballantyne, R., \& Packer, J. (2002). Nature-based excursions: School students' perceptions of learning in natural environments. International Research in Geographical and Environmental Education, 11(3), 218-236. https://doi.org/10.1080/10382040208667488

Chawla, L. \& Flanders Cushing, D., (2007) Education for strategic environmental behavior, Environmental Education Research, 13:4, 437-452, DOI: 10.1080/13504620701581539. https://doi.org/10.1080/13504620701581539

McGregor, D. (2009). Linking traditional knowledge and environmental practice in Ontario. Journal of Canadian Studies, 43(3), 69-100. https://doi.org/10.3138/jcs.43.3.69

Monroe, M. C., Plate, R. R., Oxarart, A., Bowers, A., \& Chaves, W. A. (2017). Identifying effective climate change education strategies: A systematic review of the research. Environmental Education Research, 25(6), 791-812. https://doi.org/10.1080/13504622.2017.1360842

NASA. (2021, June 21). The causes of climate change. Climate Change: Vital Signs of the Planet. https://climate.nasa.gov/causes/

Okui, K., Sawada, Y., \& Yoshida, T. (2021). "Wisdom of the elders" or "Loss of experience" as a mechanism to explain the decline in traditional ecological knowledge: A case study on 
Awaji island, Japan. Human Ecology, 49(3), 353-362.

https://doi.org/10.1007/s10745-021-00237-w

Otto, S., \& Pensini, P. (2017). Nature-based environmental education of children: Environmental knowledge and connectedness to nature, together, are related to ecological behaviour. Global Environmental Change, 47, 88-94.

https://doi.org/10.1016/j.gloenvcha.2017.09.009

Paterson, P. O., \& Elliott, L. N. (2006). Struggling reader to struggling reader: High school students' responses to a cross-age tutoring program. Journal of Adolescent \& Adult Literacy, 49(5), 378-389. https://doi.org/10.1598/jaal.49.5.2

Saylan, C., \& Blumstein, D. T. (2011). The failure of environmental education (And how we can fix it). University of California Press.

Volk, T. L., Hungerford, H. R., \& Tomera, A. N. (1984). A national survey of curriculum needs as perceived by professional environmental educators. The Journal of Environmental Education, 16(1), 10-19. https://doi.org/10.1080/00958964.1984.9942696

Zelezny, L. C. (1999). Educational interventions that improve environmental behaviors: A meta-analysis. The Journal of Environmental Education, 31(1), 5-14. https://doi.org/10.1080/00958969909598627 